Pre-print of article published as: R. Kenny, C. Law, J.M. Pearce, “Towards Real Energy Economics: Energy Policy Driven by Life-Cycle Carbon Emission”, Energy Policy 38, pp. 1969-1978, 2010. Available: http://dx.doi.org/10.1016/j.enpol.2009.11.078

\title{
Towards Real Energy Economics: Energy Policy Driven by Life-Cycle Carbon Emission
}

\author{
R. Kenny ${ }^{1, *}$, C. Law ${ }^{1, *}$, J.M. Pearce ${ }^{1, \dagger}$ \\ ${ }^{1}$ Department of Mechanical and Materials Engineering, Queen's University
}

\begin{abstract}
Alternative energy technologies (AETs) have emerged as a solution to the challenge of simultaneously meeting rising electricity demand while reducing carbon emissions. However, as all AETs are responsible for some greenhouse gas (GHG) emissions during their construction, carbon emission "Ponzi Schemes" are currently possible, wherein an AET industry expands so quickly that the GHG emissions prevented by a given technology are negated to fabricate the next wave of AET deployment. In an era where there are physical constraints to the GHG emissions the climate can sustain in the short term this may be unacceptable. To provide quantitative solutions to this problem, this paper introduces the concept of dynamic carbon lifecycle analyses, which generate carbon neutral growth rates. These conceptual tools become increasingly important as the world transitions to a low-carbon economy by reducing fossil fuel combustion. In choosing this method of evaluation it was possible to focus uniquely on reducing carbon emissions to the recommended levels by outlining the most carbon-effective approach to climate change mitigation. The results of using dynamic life-cycle analysis provide policy makers with standardized information that will drive the optimization of electricity generation for effective climate change mitigation.
\end{abstract}

Keywords: greenhouse gas emissions; renewable energy; climate change mitigation

*The first two authors contributed equally to this work and should be considered co-first authors. $\dagger$ Corresponding author: 60 Union Street, Kingston, Ontario, K7L 3N6 Canada, ph:613-5333369, pearce@me.queensu.ca 
Pre-print of article published as: R. Kenny, C. Law, J.M. Pearce, “Towards Real Energy Economics: Energy Policy Driven by Life-Cycle Carbon Emission", Energy Policy 38, pp. 1969-1978, 2010. Available: http://dx.doi.org/10.1016/j.enpol.2009.11.078

\section{Introduction}

It is now clear that anthropogenic climate destabilization represents both a market failure and an immediate threat to human welfare, ecosystems, and the temperate climate for which life on earth has evolved (Stern, 2007; IPCC, 2008a). Equivalent carbon emissions from industrial society, primarily caused by the combustion of fossil fuels, have risen to $49 \mathrm{GtCO}_{2}$-eq/yr precipitating a concomitant increase in atmospheric carbon concentration from a preanthropocene level of 280 ppmv to 379 ppmv in 2005 (IPCC, 2008a). Greenhouse gas (GHG) concentrations at the current level cause a global disequilibrium and even emissions stabilization at these intensities will produce a $\sim 2^{\circ} \mathrm{C}$ temperature rise (Hansen et al., 2008). This timedependent relationship demands that future generations compensate for present emissions. In order to avoid further disruption to the earth's thermal equilibrium and negative effects on human society, it has been recommended that greenhouse gas emissions be stabilized at levels below 350 ppmv (Hansen et al., 2008).

The imperative to act on climate change has affected nearly every sector; however an emphasis has been placed on the electricity sector due to its contribution of $25.9 \%$ of world carbon emissions (IPCC, 2008b). As current fossil-fuel generation emits between 400 and 989 tonnes of carbon per gigawatt-hour of electricity produced, it appears as though three options are at the forefront of climate change mitigation:

1) Humankind will have to reduce its electricity consumption

2) Conventional sources of energy will have to become less carbon intensive

3) New, less carbon intensive electric power generation technologies will have to be deployed

This paper will examine the third of these three options.

Alternative energy technologies (AETs), which do not directly emit GHGs during energy conversion, will play a dominant role in offsetting emissions from conventional energy technologies (ETs) (Sims et al., 2003; IPCC, 2008b). However, in order to make a significant impact in the 18930 TWh of electricity generated globally per year (IEA, 2008a), any given AET must be deployed at a relatively fast growth rate. Previous literature has explored the large scale deployment of AETs as a method of mitigating climate change (Sims, 2004; IEA, 2008b). To aid and compliment this research extensive work has been completed detailing the life-cycle analyses for carbon emissions of these energy technologies (WEC, 2004). A static life cycle analysis (LCA) with a carbon or energy focus compares electricity output of an ET to the carbon or energy embodied in the materials, manufacturing, construction, transportation, operation and decommissioning of the technology. While static LCAs have been broadly explored, the notion of using the carbon mitigation potential of a technology in an aggregated life-cycle context has not yet been investigated. Instead static LCAs have been used to guide relevant policy (IPCC, 2008b; WEC, 2004). This practice provides AETs with the opportunity to expand at such a rapid rate that emissions associated with the deployment of the technology surpasses carbon mitigated by the technology, making it a net GHG emitter throughout a particular growth phase. This may be unacceptable in an era where there are physical constraints to the GHG emissions the climate can sustain in the short term. 
Pre-print of article published as: R. Kenny, C. Law, J.M. Pearce, “Towards Real Energy Economics: Energy Policy Driven by Life-Cycle Carbon Emission", Energy Policy 38, pp. 1969-1978, 2010. Available: http://dx.doi.org/10.1016/j.enpol.2009.11.078

To overcome this challenge, this paper introduces the concept of a "dynamic life cycle analysis" in a carbon emissions context, which takes into account both the carbon mitigation potential and the embodied carbon emissions of a technology. It thus provides a context in which differences between energy technologies can be quantitatively analyzed. This paper will show how the application of dynamic carbon LCAs can address the policy gap between prioritization of deployment of energy technologies and their corresponding emissions and energy requirements. First this paper will outline previous academic work in calculation of carbon payback times and dynamic LCAs. In order to provide a context for the concept of a dynamic LCA, previous work in the area of static LCAs will first be reviewed. Then a mathematical derivation will be provided of the quantitative indicator for a dynamic carbon LCA, known as the carbon-neutral growth rate. An example detailing integration of dynamic LCAs into energy policy is shown, followed by a discussion of the implications of this tool for energy policy.

\section{Background}

Scientists such as Hondo (2005) and Fthenakis \& Alsema (2006) have conducted static analyses on specific technologies in order to provide emission comparisons between several ETs. Such comparisons of static LCAs have emerged as policy guiding tools. The World Energy Council (WEC) has published a report detailing and comparing carbon emissions associated with energy technologies. This report is one of the closest attempts at providing a global perspective on the embodied carbon of energy technologies.

The embodied carbon of any product refers to the carbon emissions affiliated with the product over its lifetime and is the primary factor in determining the carbon mitigation potential of a technology (Hondo, 2005). In general, LCAs cover carbon emitted by ETs in two distinct areas: emissions associated with construction - fixed emissions - and emissions occurring during operation - variable emissions. Fixed emissions account for the embodied carbon in construction materials (e.g. steel, concrete, fiberglass, silicon), the transportation between manufacturing and building sites, and other initial one time carbon investments. These emissions are generally a function of power plant size and as such are expressed in mass per unit power (tonnes per MW). By contrast, variable emissions are incurred while the technology is producing electricity and are primarily associated with maintenance of the technology. These emissions are expressed in mass of carbon per unit energy (tonnes per MWh)

The distinction between fixed and variable carbon emissions is relevant to this paper because the breakdown of these emissions determines the carbon payback time of a carbon mitigation technology. Fargione et al. (2008) use a life-cycle analysis of biofuels to demonstrate the concept of a "carbon debt": the amount of carbon that is released into the atmosphere over the first 50 years of biofuel production. Carbon mitigated per year is determined by subtracting the emissions from biofuels from the life-cycle emissions of fossil fuels. These values are used to determine the carbon payback time (CPT) of a given biofuel. This same concept can be generalized for any technology and the payback time is given by:

$t_{C P}=\frac{C O_{2 \text { fossil }}-C O_{2 A E T}}{d e b t}[$ years $]$ 
Pre-print of article published as: R. Kenny, C. Law, J.M. Pearce, “Towards Real Energy Economics: Energy Policy Driven by Life-Cycle Carbon Emission”, Energy Policy 38, pp. 1969-1978, 2010. Available: http://dx.doi.org/10.1016/j.enpol.2009.11.078

Tahara et al. (1997) conducted LCAs to determine carbon payback times of energy technologies. Carbon payback time is determined by comparing the carbon emitted in construction and operation of both the carbon mitigation technology and the power plant being replaced. This approach evaluates each technology not only based on its own merit but against the technology it is displacing: the carbon payback time of a hydroelectric power plant when replacing a coal plant, for example, was found as:

$$
t_{C P(\text { hydrovscoal })}=\frac{\frac{C O_{2 C, \text { hydro }}}{E_{\text {hydro }}}-\frac{C O_{2 C, \text { coal }}}{E_{\text {coal }}}}{\frac{C O_{2 O, \text { coal }}}{E_{\text {coal }}}-\frac{C O_{2 O, \text { hydro }}}{E_{\text {hydro }}}}[\text { years }]
$$

Where $\mathrm{E}_{\text {Technology }}$ (in this case, "technology" refers to either hydro or coal) is the amount of energy produced by the technology over its lifetime, $\mathrm{CO}_{2} \mathrm{C}$, technology represents the carbon emissions associated with the construction of each power plant (fixed emissions) and $\mathrm{CO}_{2} \mathrm{O}$, technology represents the carbon emitted throughout the plant's operation (variable emissions).

Life-cycle assessment has also been used in the context of expansion of energy-producing technologies. Pearce (2008a, 2008b) outlines the concept of "energy cannibalism" where the energy produced by a given technology is consumed by the energy embodied in new power plants of the same type. The annual growth rate at which no net energy is produced by a technology is known as the energy-neutral growth rate or the "cannibalistic growth rate". The energy payback time $\left(\mathrm{t}_{\mathrm{EP}}\right)$ is found to be proportional to the reciprocal of the cannibalistic growth rate (Pearce, 2008a):

$$
t_{E P}=\frac{1}{r_{\text {can }}}=\frac{E_{E}}{E_{P}}[\text { years }]
$$

where $r_{c a n}$ is the cannibalistic growth rate, $E_{E}$ is the energy embodied in the energy technology, and $E_{P}$ is the clean energy produced each year. This effect has also been studied in the context of country-specific policy, where Mathur et al. (2004) first use the term "dynamic LCA" which takes into account the effects of energy use in expansion of energy-producing technologies. However, Mathur et al. do not outline the application of dynamic LCAs to carbon mitigation.

The information contained in cannibalistic growth rates is especially relevant when considering whether to use one or many energy technologies to mitigate greenhouse gases. Use of only one technology necessitates a larger growth rate in order to meet energy demand. The increased expansion rate may exceed the cannibalistic growth rate signifying unsustainable growth that negates the technology's ability to mitigate climate change (Pearce, 2009). In order to avoid this situation the literature suggests that multiple low-energy, low-carbon technologies such as alternative energy technologies must be used to reduce GHG emissions from the power sector (Sims et al., 2003; IEA, 2008b).

Alternative energy technologies have evolved from small off grid operations to a viable electricity generation option on both small and large scales (IEA, 2008b). Hydroelectric and nuclear power currently provide approximately $30 \%$ of the world's electricity while other AETs provide $2.3 \%$ (IEA, 2008a). This compares favorably to the $0.6 \%$ of electricity production that AETs provided in 1973: AETs have increased their market share by more than $1 \%$ while demand 
Pre-print of article published as: R. Kenny, C. Law, J.M. Pearce, “Towards Real Energy Economics: Energy Policy Driven by Life-Cycle Carbon Emission”, Energy Policy 38, pp. 1969-1978, 2010. Available: http://dx.doi.org/10.1016/j.enpol.2009.11.078

for electricity has tripled (IEA, 2008a). Current growth for individual technologies varies from 2 - 110\% (WEC, 2004; Solarbuzz, 2009). Growth of AETs is primarily dependent upon policy, public opinion, government subsidies and incentives, resource availability and access to capital (Neuhoff, 2005).

The superposition of AETs' small share of global electricity generation and the time sensitive nature of climate change has raised the question of the feasibility of large scale deployment of AETs. Technical potential of AETs far surpass global energy demand and the technology is proven and commercially available, although economic hurdles must still be overcome (Johansson, 1993; Turner, 1999; Pearce, 2002; Neuhoff, 2005; de Vries, 2007; Jacobson, 2009).

\section{Theory}

The literature outlined above has made substantial inroads (towards) including life-cycle carbon emissions in energy policy; however, a quantitative measure for dynamic LCAs for carbon is still needed. The following section explains and derives a tool that can be used to directly compare dynamic LCAs of energy technologies.

The "carbon neutral growth rate" can be defined as the rate at which the aggregate carbon mitigation of an energy technology as a whole (for example, all wind power projects in the world) is offset by the carbon emitted in the construction of new plants. When the growth of a technology exceeds this growth rate it is possible for a carbon emission "Ponzi Scheme" to develop, where an AET industry grows so quickly that the GHG emissions prevented by a given technology are negated to fabricate the next wave of AET deployment. While in a traditional Ponzi Scheme old investors profit from new investors, new "investors" in a "Carbon Ponzi Scheme" (technologies that are capable of mitigating GHG emissions) negate the offsets provided by old "investors". Put another way, initial carbon "investors" offset emissions for future installed capacity. The carbon neutral growth rates and dynamic LCAs evaluate the lifetime carbon emissions of technologies providing a more comprehensive approach to technology evaluation.

To quantify this effect, consider all of the power plants using one energy technology, for example wind power. These plants have a total power generating capacity $P_{T}(G W)$. The capacity of new plants produced in a given year is denoted as $\mathrm{p}_{\mathrm{n}}$.

$p_{n}=r P_{T}\left[\right.$ GWyear $\left.^{-1}\right]$

In this equation, $r$ is the percent growth of new plants annually [year ${ }^{-1}$. Each new plant has fixed carbon emissions associated with its production, such as carbon embodied in steel and concrete inputs. These are denoted as $\mathrm{C}_{\mathrm{IN}}$, or the total metric tonnes of carbon inputs required in the production of $1 \mathrm{GW}$ of additional capacity [t/GW]. The total carbon required in the production of new power plants in one year, $\mathrm{C}_{\mathrm{p}}$, can be given as:

$C_{p}=C_{I N} r P_{T}\left[\right.$ tonnesyear $\left.^{-1}\right]$

The carbon mitigation potential of a given energy technology is highly dependent on the carbon content of the energy technologies it replaces (Sims et al., 2003). A solar photovoltaic panel installed in an area where coal power is prevalent will displace more carbon than an identical panel installed where the grid emits less carbon per unit energy produced. An ET mitigates 
Pre-print of article published as: R. Kenny, C. Law, J.M. Pearce, “Towards Real Energy Economics: Energy Policy Driven by Life-Cycle Carbon Emission”, Energy Policy 38, pp. 1969-1978, 2010. Available: http://dx.doi.org/10.1016/j.enpol.2009.11.078

carbon at a rate proportional to the difference between its variable carbon emissions and the carbon intensity (amount of carbon emitted per unit energy produced, measured in grams $\mathrm{CO}_{2}$ per $\mathrm{kWh}$ ) of the grid into which it is introduced. As such, the carbon mitigated by an energy technology in the production of one gigawatt-hour of electricity, $\mathrm{C}_{\mathrm{MPG}}$, is:

$$
C_{M P G}=\left(C_{M I X}-C_{V A R}\right)\left[\text { tonnes } M W h^{-1}\right]
$$

$\mathrm{C}_{\mathrm{MIX}}$ refers to the tonnes of carbon produced per gigawatt-hour supplied to the grid. $\mathrm{C}_{\mathrm{VAR}}$ denotes the tonnes of carbon emitted per gigawatt-hour produced by the ET (variable emissions). The number of plant operating hours, $\mathrm{T}_{\mathrm{o}}$, in a year is given by the product of the fraction of the year that the plant is operating, known as the capacity factor $\varphi$, and the total hours in an average year. $T_{o}=\varphi * 8766[$ hrs $]$

The carbon mitigated per gigawatt-hour is multiplied by the total capacity and the number of operating hours per year, yielding the tonnes of carbon mitigated by a given technology in a year. $C_{m}=\left(C_{M I X}-C_{V A R}\right) P_{T} \varphi * 8766 \quad\left[\right.$ tonnesyear $\left.^{-1}\right]$

Setting equal the carbon associated with production, $\mathrm{C}_{\mathrm{p}}$, (equation 5 ) and the total carbon mitigation, $\mathrm{C}_{\mathrm{m}}$, (equation 8 ) for a given energy technology, yields:

$$
\left(C_{M I X}-C_{V A R}\right) P_{T} \varphi * 8766=C_{I N} r P_{T}
$$

Rearranging equation 9 to solve for the growth rate at which no net carbon is mitigated provides the rate at which carbon-neutral growth, $\mathrm{r}_{\mathrm{CN}}$, occurs:

$$
r_{C N}=\frac{\left(C_{M I X}-C_{V A R}\right) \varphi * 8766}{C_{I N}}
$$

Note that this rate is not dependent on the total power generating capacity. At this rate, an energy technology as a whole mitigates no net carbon dioxide emissions.

It is important to differentiate between energy policy dependent on the maximum carbonneutral growth rates and carbon payback time. Tahara et al (1997) take into account the EPT of an AET and difference in embodied carbon between AETs and traditional generation, but does not account for the grid to which the AET is connected. The carbon-neutral growth rate is dependent upon both a given technology and the grid into which it is connected, instead of only the technology it replaces. While the carbon payback time compares the additional carbon created in the manufacture of a technology to the carbon it mitigates throughout its lifetime, the carbon-neutral growth rate is a dynamic measure of the emissions for which the installation of the technology is directly responsible.

To further illustrate the importance of dynamic life-cycle analysis, consider two hypothetical technologies (numbered 1 and 2) used in two $100 \mathrm{MW}$ power plants. Plant 1 has fixed emissions of 12,500 tonnes/MW and variable emissions of $50 \mathrm{~g} / \mathrm{kWh}$, while Plant 2 has fixed emissions of 25,000 tonnes/MW and variable emissions of $0 \mathrm{~g} / \mathrm{kWh}$. Over a lifetime of 250,000 hours, each plant has average lifecycle emissions of $100 \mathrm{~g} / \mathrm{kWh}$ and by static life-cycle assessment, each would be considered equally desirable for deployment. However, the importance of dynamic conditions are clear if each energy technology were to expand at a hypothetical rate of $17 \%$ per year with a capacity factor of 0.8 , in a grid with a carbon intensity of $600 \mathrm{~g} / \mathrm{kWh}$. At this rate, all of the carbon mitigated by Plant 2 is emitted in construction of new plants and technology 2 mitigates no net carbon. However, this is not the case for energy 
Pre-print of article published as: R. Kenny, C. Law, J.M. Pearce, “Towards Real Energy Economics: Energy Policy Driven by Life-Cycle Carbon Emission”, Energy Policy 38, pp. 1969-1978, 2010. Available: http://dx.doi.org/10.1016/j.enpol.2009.11.078

technology 1 , which can grow nearly twice as quickly (at over $30 \%$ per year) before it causes a net emission of carbon dioxide.

\section{Methodology}

While the hypothetical scenario between Plant 1 and 2 shows the importance of dynamic life-cycle assessment in deployment of energy technologies, it does not take into account many realities and interactions present in the current electricity market. In order to illustrate the applicability of the concept of carbon neutral growth rates guiding deployment of ETs, a model was developed to apply dynamic LCAs to replacement of carbon-intensive electricity infrastructure in a global context. The model calculated global growth rates and capacity additions for ten energy technologies through 2050, incorporating carbon-neutral growth rates as well as other constraints. It was used to create an example of the complex interaction between carbon-neutral growth rates and energy technology growth. It is important to note that the example shown here does not claim to project or predict future growth of the electricity market: for more detailed analyses, see the IEA Energy Technology Perspectives and World Energy Outlook (IEA 2008a, IEA 2008b). Rather, this example scenario demonstrates the incorporation of life cycle carbon emissions into energy technology deployment models. Using the demand increase forecasts of the IEA (2008c) and 50\% carbon emissions reduction outlined by IPCC scenarios targeting 350 ppmv atmospheric carbon (IPCC 2008a, IPCC 2008b), the simulation deployed ETs from 2010 through to 2050. The annual growth of the energy technologies in the simulation was constrained by four limitations: (i) energy cannibalistic growth rate, (ii) carbon neutral growth rate, (iii) maximum grid penetration, and (iv) maximum historic growth rate.

\section{Energy Cannibalism Growth Rate}

The energy cannibalistic growth rate (equation 3) can be calculated as the inverse of the energy payback time (Pearce, 2008a) and was held constant throughout the example period. This constraint was included to ensure that the construction of energy technologies produced positive net energy at all times. Energy payback times for the ETs considered are shown in Table 1. 
Pre-print of article published as: R. Kenny, C. Law, J.M. Pearce, “Towards Real Energy Economics: Energy Policy Driven by Life-Cycle Carbon Emission", Energy Policy 38, pp. 1969-1978, 2010. Available: http://dx.doi.org/10.1016/j.enpol.2009.11.078

Table 1: Data used to determine carbon neutral and cannibalistic growth rates

\begin{tabular}{|c|c|c|c|c|c|}
\hline $\begin{array}{l}\text { Energy } \\
\text { Technology }\end{array}$ & $\begin{array}{l}\text { Current } \\
\text { Capacity }\end{array}$ & $\begin{array}{l}\text { Current } \\
\text { energy } \\
\text { produced } \\
\text { per year }\end{array}$ & $\begin{array}{l}\text { Maximum } \\
\text { Growth } \\
\text { \%/year }\end{array}$ & $\begin{array}{l}\text { Energy } \\
\text { Payback } \\
\text { Time (years) }\end{array}$ & $\begin{array}{l}\text { Emissions } \mathrm{CO}_{2} \\
\text { equivalent }\end{array}$ \\
\hline $\begin{array}{l}\text { Solar } \\
\text { Photovoltaic }\end{array}$ & $\begin{array}{l}13 \mathrm{GW}^{\text {a }} \text { grid } \\
\text { connected }\end{array}$ & $5003 \mathrm{GWh}^{\mathrm{b}}$ & $110 \%^{\mathrm{c}}$ & $1-2.7^{\mathrm{d}}$ & $21-59 \mathrm{~g} / \mathrm{kWh}^{\mathrm{d}}$ \\
\hline $\begin{array}{l}\text { Concentrating } \\
\text { solar power }\end{array}$ & $0.5 \mathrm{GW}^{\mathrm{a}}$ & $1061 \mathrm{GWh}^{\mathrm{e}}$ & $27 \%^{\mathrm{f}}$ & $\begin{array}{l}2.7-12.5 \\
\text { months }\end{array}$ & $\begin{array}{l}\text { Constr: } 24 \\
\text { g/kWh } \\
\text { Ops: } 141 \\
\text { g/kWh }\end{array}$ \\
\hline Wind & $121.2 \mathrm{GW}^{\mathrm{h}}$ & $260 \mathrm{TWh}^{\mathrm{h}}$ & $29 \%^{\mathrm{h}}$ & $0.4 \mathrm{i}-1.4^{\mathrm{j}}$ & $\begin{array}{l}\text { Constr: } 2671.2 \\
\text { (tonnes) }^{\mathrm{k}} \\
\text { Ops: } 185 \\
\text { (tonnes) }^{\mathrm{k}} \\
* 4.5 \mathrm{MW} \\
\text { turbine }\end{array}$ \\
\hline Geothermal & $10 \mathrm{GW}^{\mathrm{f}, 1}$ & $\begin{array}{l}59240 \\
G^{\prime} h^{\mathrm{b}, \mathrm{e}}\end{array}$ & $3 \%^{1}$ & $5.7^{\mathrm{m}}$ & $\begin{array}{l}\text { Constr: } 5.3 \\
\text { g/kWh } \\
\text { Ops: } 9.7 \mathrm{~g} / \mathrm{kWh}^{\mathrm{n}}\end{array}$ \\
\hline $\begin{array}{l}\text { Small Hydro } \\
(>10 \mathrm{MW})\end{array}$ & $12 \mathrm{MW}^{\circ}$ & $2510 \mathrm{TWh}^{\circ}$ & $7 \% \mathrm{f}^{\mathrm{f}}$ & $11.8^{\mathrm{m}}$ & $\begin{array}{l}\text { (10MW)-Const: } \\
9.3 \mathrm{~g} / \mathrm{kWh} \mathrm{h}^{\mathrm{n}} \\
\text { Ops: } 1.9 \mathrm{~g} / \mathrm{kWh}^{\mathrm{n}}\end{array}$ \\
\hline $\begin{array}{l}\text { Biomass } \\
\text { Power }\end{array}$ & $52 \mathrm{GW}^{\mathrm{a}}$ & $170 \mathrm{TWh}^{\mathrm{p}}$ & $3 \%^{\mathrm{f}}$ & $1.92^{\mathrm{q}}$ & $\begin{array}{l}15.1-49 \\
\mathrm{t} / \mathrm{GWh}^{\mathrm{r}}\end{array}$ \\
\hline Oil & $156 \mathrm{GW}^{\mathrm{s}}$ & $1096 \mathrm{TWh}^{\mathrm{s}}$ & $3 \% \%^{t}$ & $13.8^{\mathrm{u}}$ & $\begin{array}{l}\text { Ops: } 610-700 \\
\text { t/GWh } \\
\text { Constr: } 75-120 \\
\text { t/GWh }\end{array}$ \\
\hline NGCC & $1060 \mathrm{GW}^{\mathrm{v}}$ & $3807 \mathrm{TWh}^{\mathrm{s}}$ & $8 \% \mathrm{t}$ & $\overline{7^{u}}$ & $\begin{array}{l}\text { Ops: } 350-375 \\
\text { t/GWh } \\
\text { Constr: } 50-150 \\
\text { t/GWh }\end{array}$ \\
\hline Nuclear & $369 \mathrm{GW}^{\mathrm{s}}$ & $2793 \mathrm{TWh}^{\mathrm{s}}$ & $15 \% \%^{t}$ & $2.5^{\mathrm{u}}$ & $\begin{array}{l}\text { Construction: } \\
42 \mathrm{~g} / \mathrm{kWh}^{\mathrm{v}} \\
\text { Operation: } \\
40 \mathrm{~g} / \mathrm{kWh}^{\mathrm{v}}\end{array}$ \\
\hline Coal & $1261 \mathrm{GW}^{\mathrm{w}}$ & $7755 \mathrm{TWh}^{\mathrm{s}}$ & $10 \%{ }^{t}$ & $3.18^{\mathrm{u}}$ & $\begin{array}{l}\text { Combustion: } \\
\text { 881.6 g/kWh } \\
\text { Const/decom: }\end{array}$ \\
\hline
\end{tabular}


Pre-print of article published as: R. Kenny, C. Law, J.M. Pearce, “Towards Real Energy Economics: Energy Policy Driven by Life-Cycle Carbon Emission", Energy Policy 38, pp. 1969-1978, 2010. Available: http://dx.doi.org/10.1016/j.enpol.2009.11.078

\begin{tabular}{|l|l|l|l|l|l|}
\hline & & & & & $1.1 \mathrm{~g} / \mathrm{kWh}^{\mathrm{x}}$ \\
& & & & $\begin{array}{l}\text { Non-combustion } \\
\text { operation: } 42.1 \\
\mathrm{~g} / \mathrm{kWh}\end{array}$ \\
\hline Large Hydro & $867 \mathrm{GW}^{\mathrm{s}}$ & $3121 \mathrm{TWh}^{\mathrm{s}}$ & $2 \% \mathrm{r}^{\mathrm{r}}$ & $0.5^{\mathrm{u}}$ & $2-45 \mathrm{Kt} / \mathrm{TWh}^{\mathrm{u}}$ \\
\hline
\end{tabular}

\section{Carbon Neutral Growth Rate}

The growth of each energy technology was restricted to the carbon-neutral growth rate. The initial carbon neutral growth rates are shown in Table 3. These were derived from the principles explored above and calculated using equation 10. These limitations changed over time because the carbon content of electricity produced by the grid $\left(\mathrm{C}_{\mathrm{MIX}}\right.$ in equation 10$)$ decreased as carbon-intensive fuels were removed. Therefore, the carbon-neutral growth rate was recalculated for each technology every year.

\section{Maximum Grid Penetration}

One of the major challenges associated with large scale deployment of AETs is the limitation of the electrical grid. Generally, there is a maximum percentage of total power production that can be provided by intermittent AETs such as wind or solar. These percentages are regulated on a more local level and are often implemented in order to ensure that demand can be met throughout the day. Typically this maximum capacity is set at approximately twenty percent but varies depending on the region and associated back up power capabilities (Utility Wind Integration Group, 2006). However, it is important to note that increased use of smart grids, backup power, energy storage and other technology increases this number, but as none of these technologies is in widespread use, the conservative estimate of $20 \%$ was used.

\section{Maximum Possible Growth Rates}

The primary purpose of this study was to demonstrate carbon-neutral growth rates as a driver for energy policy and as such an economic analysis of large scale renewable deployment was not conducted. However, in order to incorporate constraints such as construction capacity into the model, the maximum historic growth rate of each technology provided a constraint on growth. This approach accounts for the industries' ability to grow quickly if required and provides a maximum feasible growth rate. However, this restriction places newer technologies such as geothermal energy at a disadvantage and is not necessarily reflection on the potential future performance of the technologies.

Table 1 contains the raw data used to determine initial installed capacities, current energy produced per year, maximum growth rate, energy payback times and emissions. The current installed capacities were not available for this current year and as such all initial capacities were normalized by multiplying the capacity by the growth rate for the number of years that the data was behind. Table 2 contains lifetimes and capacity factors for the investigated technologies. 
Pre-print of article published as: R. Kenny, C. Law, J.M. Pearce, “Towards Real Energy Economics: Energy Policy Driven by Life-Cycle Carbon Emission", Energy Policy 38, pp. 1969-1978, 2010. Available: http://dx.doi.org/10.1016/j.enpol.2009.11.078

Table 2: Capacity factors and lifetimes for Energy Technologies

\begin{tabular}{|c|c|c|}
\hline Energy Technology & $\begin{array}{l}\text { Capacity } \\
\text { Factor }\end{array}$ & $\begin{array}{l}\text { Lifetime } \\
\text { (years) }\end{array}$ \\
\hline Oil & $0.42^{r}$ & $40^{u}$ \\
\hline NGCC & $0.72^{r}$ & $35^{u}$ \\
\hline Coal & $0.7^{r}$ & $35^{u}$ \\
\hline Hydro & $0.58^{r}$ & $100^{r}$ \\
\hline Nuclear & $0.84^{r}$ & $40^{u}$ \\
\hline Solar Photovoltaic & $0.2^{c}$ & $30^{d}$ \\
\hline CST & $0.7^{f}$ & $25^{g}$ \\
\hline Wind & $0.28^{r}$ & $20^{r}$ \\
\hline Geothermal & $0.6^{m}$ & $30^{n}$ \\
\hline Small Hydro & $0.8^{r}$ & $100^{r}$ \\
\hline Biomass Power & $0.79^{q}$ & $40^{q}$ \\
\hline \multicolumn{3}{|c|}{$\begin{array}{l}\text { Sources: (a) IEA (2009b) (b) IEA (2008d) (c) SolarBuzz } \\
\text { (2009) (d) Fthenakis and Alsema (2006) (e) IEA (2008e) (f) } \\
\text { IEA (2007) (g) Lechon } \text { et al. (2008) (h) WWEA (2008) (i) } \\
\text { Martinez et al. (2009) (j) Celik et al. (2007) (k) Tremeac and } \\
\text { Meunier (2009) (l) Fridleifsson } \text { et al. (2008) (m) Mortimer } \\
\text { (1991) (n) Hondo (2005) (o) Demirbas } \text { et al. (2004) (p) UNDP } \\
\text { (2004) (q) Mann and Spath (1997) (r) WEC (2004) (s) IEA } \\
\text { (2008a) (t) IEA (2009a) (u) Gagnon } \text { et al. (2002) (v) Fthenakis } \\
\text { \& Kim (2007) (w) IEA (2008c) (x) Odeh \& Cockerill (2008) }\end{array}$} \\
\hline
\end{tabular}

\subsection{Operation of Model}

The model selected the lowest of the energy cannibalism growth rate, carbon neutral growth rate, maximum grid penetration, and the maximum feasible growth rate. This ensured that growth of any one technology did not exceed the constraints imposed upon its expansion. In the event that the lowest growth rate was negative, the growth of a technology was set to zero: as will be explained later, the reduction in carbon-intensive technologies was dealt with in a separate function. Once the maximum possible annual growth for each replacement technology had been found, the technologies were ranked according to their carbon-neutral growth rates. The increase in electricity demand was calculated using rates from the IEA World Energy Outlook, which predicts an annual growth rate of 3.2\% until 2015 followed by a decrease in demand causing the growth to taper off to a rate of $2 \%$ through to 2030 (IEA, 2008c). Projections past 2030 are not available and as such it was assumed that the demand would continue to grow at an annual rate of $2 \%$. In addition, variable carbon emissions were reduced by an increasing amount each year, such that a 50\% reduction was achieved by 2050 . In order to simulate these reductions, plants of the most carbon-intensive electricity generation technologies 
Pre-print of article published as: R. Kenny, C. Law, J.M. Pearce, “Towards Real Energy Economics: Energy Policy Driven by Life-Cycle Carbon Emission”, Energy Policy 38, pp. 1969-1978, 2010. Available: http://dx.doi.org/10.1016/j.enpol.2009.11.078

were taken off line each year. The carbon emissions were found by summing the emissions from each source, given by:

$$
C O_{2 \text { source } 1}[\text { tonnes }]=P_{T}[G W] * \text { carbonintensity }\left[\frac{t}{G W h}\right] * 8766 * \varphi
$$

combined with new increases in demand, was used as the amount of additional capacity to be added in the simulated year. This additional capacity was met by growing the best-ranked carbon mitigation technology at its maximum rate, then growing each subsequently ranked technology until all additional capacity requirements were met. Possible capacity contributions from technologies unable to mitigate carbon as effectively were set to zero, as they were not required. Capacity growth for the carbon-intensive technologies being taken off line was negative, and the resulting capacity growth for each technology was added to current capacities from equation 3 to provide:

$$
P_{T(n+1)}=P_{T(n)}+p_{n} * 1 \text { year }[G W]
$$

Variable carbon emissions and carbon intensity of the grid $\left(\mathrm{C}_{\mathrm{MIX}}\right)$ were calculated using capacities of each technology:

$$
C_{M I X}=\frac{C O_{2 \text { source1 }}+C O_{2 \text { source } 2}+\ldots[\text { tonnes }]}{D[G W]}
$$

where $\mathrm{D}$ is demand. Replacement rates were calculated by assuming that each energy technology had a constant lifespan, and that the plants that came online one lifetime ago would have to be replaced. IEA data was used to approximate past capacity additions (SourceOECD, 2009). The capacity replacements were added to capacity growth found previously in order to calculate fixed carbon emissions each year.

$$
C O_{2 \text { fixed }}[\text { tonnes }]=C_{\text {fix }}\left[\frac{\text { tonnes }}{G W}\right] *\left(p_{r}+p_{a}\right)[G W]
$$

where $\mathrm{C}_{\text {fix }}$ is the fixed carbon, $\mathrm{p}_{\mathrm{r}}$ is replacement capacity and $\mathrm{p}_{\mathrm{a}}$ is additional capacity. All of the data calculated in the previous year of the computer program was then used to calculate the new carbon-neutral growth rates for each technology. As such, changes in carbon-neutral growth rates and their interactions with capacity additions could be calculated. It should be noted here that in this simple analysis the likely innovations in technology that would result in lower $\mathrm{C}_{\mathrm{IN}} \mathrm{S}$, which would also change with time, were not considered.

\section{Results}

The first criterion used to evaluate the energy producing technologies was the carbon neutral growth rate. Table 3 shows the investigated technologies ranked according to current carbon neutral growth rates as determined from the analysis of equations 4 through 10 . 
Pre-print of article published as: R. Kenny, C. Law, J.M. Pearce, “Towards Real Energy Economics: Energy Policy Driven by Life-Cycle Carbon Emission”, Energy Policy 38, pp. 1969-1978, 2010. Available: http://dx.doi.org/10.1016/j.enpol.2009.11.078

Table 3: Rankings of current technologies according to carbon neutral growth rates

\begin{tabular}{|l|c|}
\hline Electric Energy Technology & $\begin{array}{c}\text { Carbon } \\
\text { Neutral } \\
\text { Growth } \\
\text { Rate (\%) }\end{array}$ \\
\hline Geothermal & $249 \%$ \\
\hline Wind & $91 \%$ \\
\hline Biomass & $50 \%$ \\
\hline Concentrating Solar Thermal & $43 \%$ \\
\hline Small Hydro & $43 \%$ \\
\hline Solar Photovoltaic & $41 \%$ \\
\hline Nuclear & $22 \%$ \\
\hline Hydro & $5 \%$ \\
\hline Natural Gas Combined Cycle & $-5 \%$ \\
\hline Oil & $-20 \%$ \\
\hline
\end{tabular}

As can be seen in Table 3, large differences exist between ETs in terms of carbon neutral growth rates. Carbon neutral growth rates are directly linked to a technology's ability to mitigate carbon: higher growth rates indicate larger carbon mitigation potential. A carbon neutral growth rate of zero indicates that a technology is neither increasing the average carbon intensity of the electricity mix nor mitigating any carbon. Negative carbon growth rates imply that adding capacity of that technology to the grid will result in an increase in GHG emissions per unit energy. It is important to note that decreasing capacity of these technologies at the given rates does not result in carbon mitigation: rather these negative rates provide a relative means of comparison between net carbon emitting technologies. While the results of this ranking in Table 3 provide a snapshot of the technologies that will be most effective for present implementation, these rates vary substantially by geographic location (e.g. wind or solar geographic distribution) and time. These variations with time are a result of changes in carbon intensity due to factors such as increases in technical efficiency, materials used and thus embodied carbon, fuel supplies, etc. Being that the carbon-neutral growth rate, carbon intensity, and capacity growth are interdependent, the model demonstrated how each variable depended on the others: growth of and changes in the world's electricity supply capacity were analyzed using the rankings provided in Table 3, which evolved following equations 11-14. The resulting changes in capacity with the constraints outlined above are shown in Figure 1. 
Pre-print of article published as: R. Kenny, C. Law, J.M. Pearce, “Towards Real Energy Economics: Energy Policy Driven by Life-Cycle Carbon Emission”, Energy Policy 38, pp. 1969-1978, 2010. Available: http://dx.doi.org/10.1016/j.enpol.2009.11.078

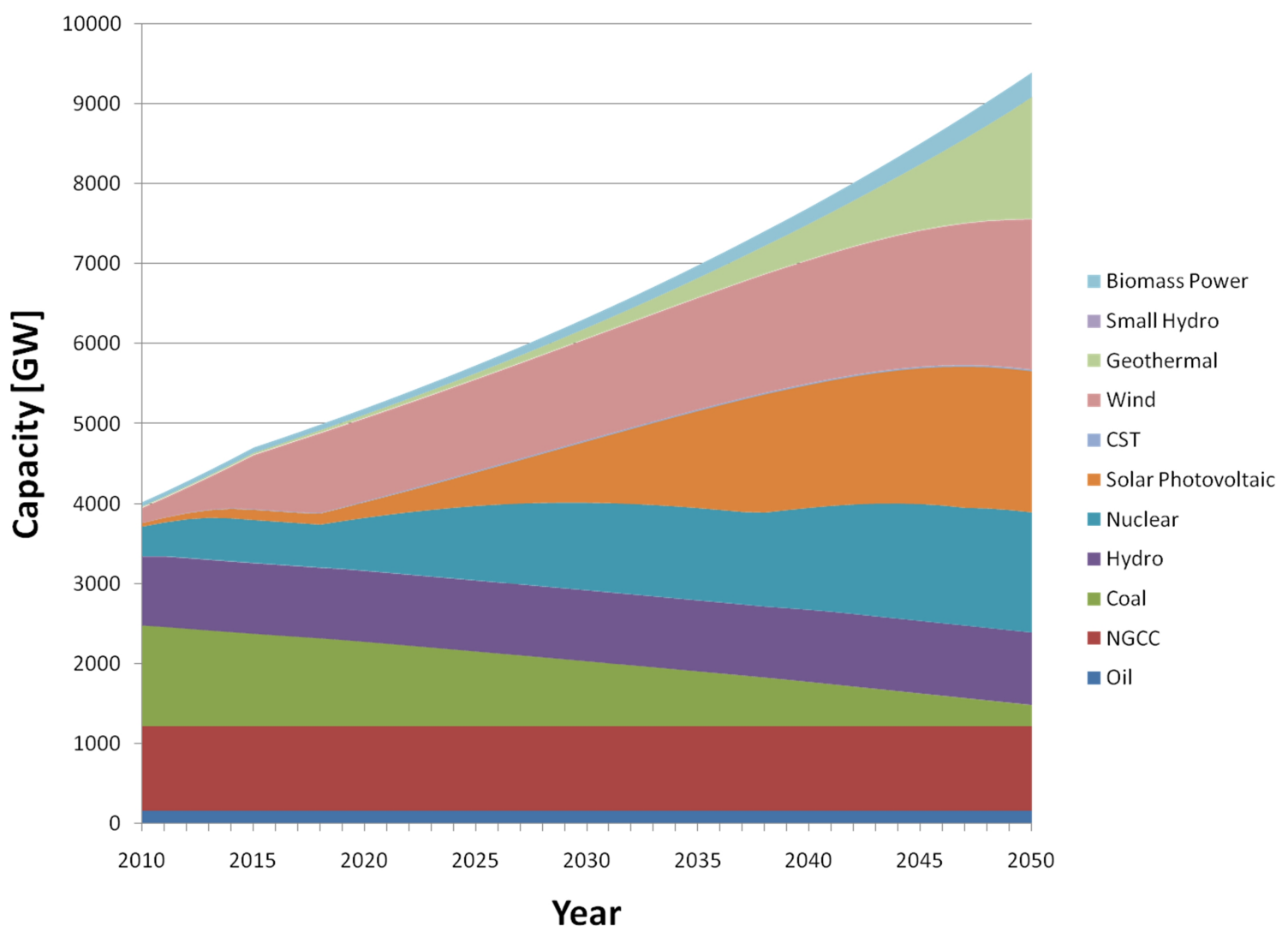

Figure 1: Modeled global electricity supply capacity (GW), 2010-2050.

Figure 1 represents the total electric power generated globally and each colored portion represents the generation capacity provided by an individual technology. The rapid 3.2\% increase in electricity consumption through 2015 creates demand for capacity additions of the most effective carbon mitigation technologies. In this example, wind power has both the initial size and the relative carbon neutrality to grow quickly. Soon after 2015, however, wind reaches the maximum $20 \%$ grid penetration and cannot keep up with the increase in demand. Solar photovoltaic technology has built up the capacity to expand and fills most new capacity additions through 2030. This trend of replacement when capacity is reached continues through the technologies listed in Table 1 until the end of the simulation.

These changes in capacity bring about a reduction in carbon emissions from energy supply of approximately $50 \%$, the amount recommended in order to avoid catastrophic climate change. The changes in carbon emissions are shown in Fig. 2, which illustrates both total variable and fixed carbon emissions for the projected deployment scenario. Variable carbon emissions decrease at a continually higher rate as the carbon intensity decreases. Fixed emissions follow a less predictable trajectory as they are dependent on the constantly changing growth of 
Pre-print of article published as: R. Kenny, C. Law, J.M. Pearce, “Towards Real Energy Economics: Energy Policy Driven by Life-Cycle Carbon Emission”, Energy Policy 38, pp. 1969-1978, 2010. Available: http://dx.doi.org/10.1016/j.enpol.2009.11.078

ETs. The production of many AET plants is responsible for an increase in fixed emissions as electricity production becomes less carbon-intensive. The AETs replacing more carbon-intensive sources tend to have higher fixed emissions, so construction of many power plants using these technologies increased the total fixed emissions. Throughout the scenario, operating emissions contribute more than four times the amount of carbon that construction does, due to the heavy reliance on fossil fuels. However, it is important to note that fixed emissions are not negligible.

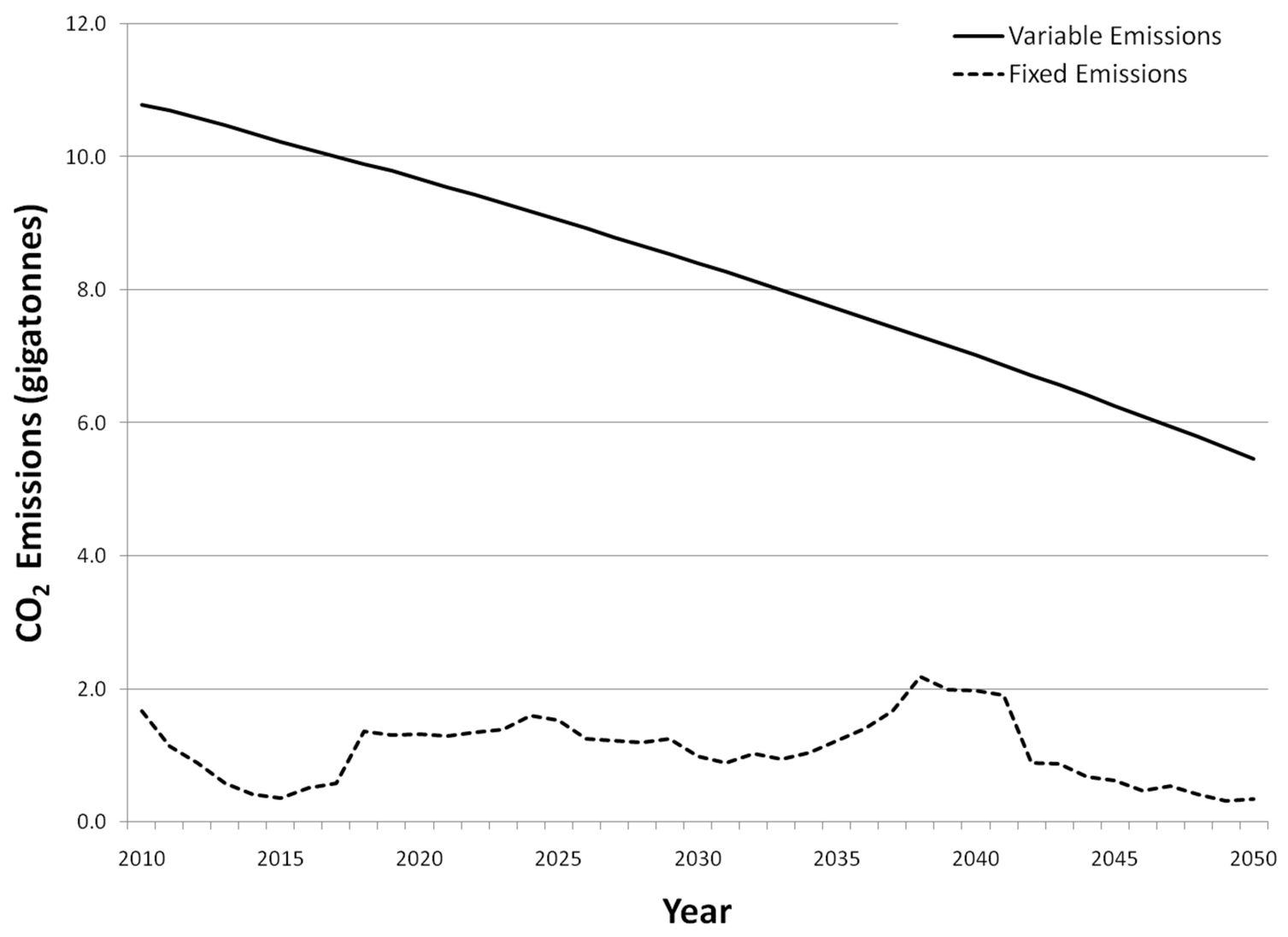

Figure 2: Carbon dioxide emissions from energy production.

The primary purpose of the model was to demonstrate the interaction between the electricity mix in Fig. 1 and the changes in the carbon-neutral growth rate. The changes in the makeup of the electricity mix affected the carbon-neutral growth rates of each technology, as these rates were dependent upon the carbon intensity of the grid. While the initial rates were outlined in Table 1 the changes in each rate over time are shown in Fig. 3. The carbon intensity of power generation closely resembles exponential decay throughout the modeled period. This curve is the quotient of two factors: the absolute decrease in variable emissions that decreases slowly at first, then quickly; and the exponential increase in capacity. The decrease in carbon 
Pre-print of article published as: R. Kenny, C. Law, J.M. Pearce, “Towards Real Energy Economics: Energy Policy Driven by Life-Cycle Carbon Emission", Energy Policy 38, pp. 1969-1978, 2010. Available: http://dx.doi.org/10.1016/j.enpol.2009.11.078

intensity results in a corresponding decrease in carbon neutral growth rate for all energy technologies, shown in Fig. 3. This temporal variation is particularly significant for technologies that have higher variable carbon emissions, as their ability to mitigate carbon emissions is rapidly reduced over time. For example, biomass power decreases from a carbon-neutral growth rate of $50 \%$ in 2010 to only $4 \%$ in 2050 . A more extreme example involves solar thermal power: because of its relatively high variable emissions as defined by Lechon et al. (2008), it transitions from mitigating carbon in 2010 to being a net carbon producer in 2037. The carbon neutral growth rate is not initially the limiting factor on growth of any AETs, as seen in Table 3. It does however limit the growth of the traditional fossil fuel generation options: the carbon neutral growth rate causes an aggressive reduction in the proportion of electricity produced by these technologies.

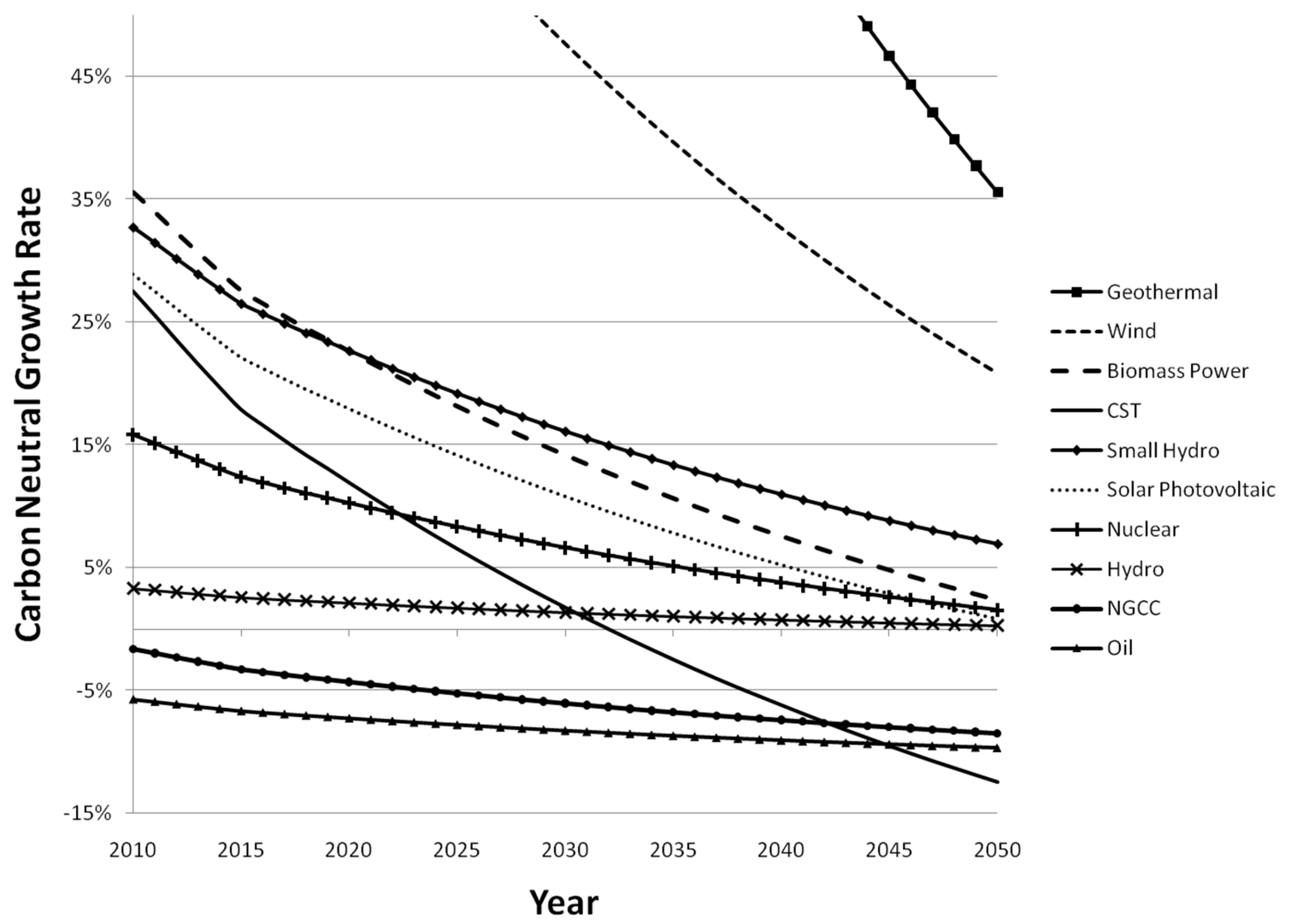

Figure 3: Carbon-neutral growth rates for each technology from 2010 to 2050. The progression of the carbon neutral growth rate for coal is not shown here in order to better depict the progression of the other technologies. The carbon neutral growth rate for coal begins at $-1311 \%$ in 2010 and decreases to $-2371 \%$ by 2050 . 
Pre-print of article published as: R. Kenny, C. Law, J.M. Pearce, “Towards Real Energy Economics: Energy Policy Driven by Life-Cycle Carbon Emission", Energy Policy 38, pp. 1969-1978, 2010. Available: http://dx.doi.org/10.1016/j.enpol.2009.11.078

\section{Discussion}

The primary goal of the simulation was to illustrate the use of dynamic LCAs to guide policy. In the simulation the target of reducing carbon emissions from electricity production by $50 \%$ and meeting demand through 2050 was accomplished while increasing the current generation capacity by $129 \%$ through the rapid deployment of alternative energy technologies. The decrease in variable emissions demanded by the simulation and subsequent AET deployment results in fluctuations in fixed emissions associated with the construction of new plants. The AETs replacing more carbon-intensive sources tend to have higher fixed emissions, so construction of many power plants using these technologies causes emissions from other industrial sectors. An example of these fluctuations is the increase the carbon emissions associated with steel and concrete production due to the large increase in nuclear power generation between 2030 and 2040. While fixed emissions are not directly caused by electricity generation, they contribute up to $19 \%$ of carbon emissions related to electricity generation. This illustrates the cross sector influence of rapid deployment of AETs and the necessity to incorporate indirect emissions in life cycle assessments. From this analysis, it is clear that any plan to reduce carbon emissions to suggested levels in the near future must be comprehensive: a decrease in absolute carbon emissions of the electricity generation sector must be accompanied by a similar decrease from other sectors. Without this provision, it is entirely possible that emissions reductions in the power generation sector would be offset by increases in emissions in other sectors.

\subsection{Applicability to Geography}

While the decrease in carbon intensity through deployment of AETs illustrates the integration of carbon-neutral growth rates to guide energy policy, the model's extrapolation of this analysis to a global scale is not entirely accurate. The world is not connected by a global grid and the carbon intensity of each power grid is different. In addition, the type of renewable resources available differs around the world: in areas with higher average wind speeds, wind energy will have a higher capacity factor, and therefore mitigate carbon more efficiently. The opposite is true where average wind speeds are lower or there is not enough space for wind turbines, meaning that real global constraints on grid penetration are likely to be lower.

The methodology presented in this paper demonstrates the use and characteristics of the carbon-neutral growth rate in its application to dynamic LCAs on a global basis. However, this algorithm will be most effective when applied regionally and ideally when applied to a particular section of the power grid. To illustrate this point, one can note that the carbon intensity of China at $788 \mathrm{~g} / \mathrm{kWh}$ is greater than that of Canada at $184 \mathrm{~g} / \mathrm{kWh}$ (SourceOECD, 2009). Using the carbon-neutral growth rate in equation 10, the carbon mitigation potential for a solar photovoltaic electricity plant would be higher if it were commissioned in China. Individual sub-technologies such as crystalline silicon PV and thin-film PV will also have different effects when installed in each electricity grid compared to the entire technical grouping of photovoltaics because of their different embodied energies, responses, and efficiencies (Pearce \& Lau, 2002).

An additional interaction between geographical location and the dynamic LCA involves the embodied carbon of various energy technologies. In the aforementioned example involving China and Canada, the most effective carbon-mitigating PV cell would be produced in Canada 
Pre-print of article published as: R. Kenny, C. Law, J.M. Pearce, “Towards Real Energy Economics: Energy Policy Driven by Life-Cycle Carbon Emission", Energy Policy 38, pp. 1969-1978, 2010. Available: http://dx.doi.org/10.1016/j.enpol.2009.11.078

and sent to China. The low carbon intensity of the electric grid in Canada and corresponding low embodied carbon of the cell would combine with the high mitigation potential in China to produce an optimized mitigation technology. If carbon mitigation is to be accomplished as efficiently as possible such analysis must begin to be considered in both production and deployment of AETs.

\subsection{Relevance to Current Policy Discussion}

While the aim of this model was not to predict future growth of energy technologies and to instead act as an example for more comprehensive simulations, the results reinforce previous work in both the institutional and academic domains. According to the simulation nuclear deployment is $16 \%$ of electricity generation in 2050 in the best emission scenario, compared to $19 \%$ and $23 \%$ of generation in the ACT and BLUE scenarios of the IEA Energy Technology Perspectives. The $1500 \mathrm{GW}$ of nuclear power in the 2050 scenario is comparable to approximately a "wedge" and a half outlined by Pacala and Socolow (2004). Wind and solar PV generation are approximately double the projections in the IEA model, but each is nearly a "wedge" at approximately $2 \mathrm{GW}$ a piece in 2050. In general, the choice of energy technology through dynamic LCA increases the total share of wind, solar, and nuclear energy compared to current policy scenarios, which are generally constrained by economic and political considerations rather than physical GHG mitigation concerns.

This analysis of ETs did not account for economic influences and constraints: carbon mitigation potential as defined by the carbon-neutral growth rate was the primary contribution to the choice of energy technologies. In choosing this method of evaluation it was possible to focus uniquely on reducing carbon emissions to the recommended level of 350 ppmv (Hansen et al., 2008) outlining the most carbon-effective approach to climate change mitigation.

\section{Limitations and Future Work}

While this simulation acts only as an example, principles of carbon neutral growth rates could be incorporated into more comprehensive modeling techniques. A more sophisticated investigation into the relationship between carbon neutrality and feasibility of large scale deployment of AETs could provide policy makers with a climate change mitigation strategy with more extensive application potential. Exploring the interactions between constrained carbon growth and influences such as competition for resources, the Not In My Backyard syndrome explored by Gibson (2005), shifts in employment and general public perceptions could assist in increasing the accuracy of the assessment covered here. In addition, the timing of fixed and variable carbon emissions discussed earlier could be incorporated into global climate models.

This analysis considers carbon emissions throughout the life cycle of each technology and as such can guide policy pertaining to both energy production and heavy industry. As previously mentioned, economics were not accounted for and there is now a need to apply current economic principals to the feasibility of the deployment strategy outlined in this study. Economic policy applied to energy production can drastically alter the electricity production landscape (Neuhoff, 2005) and move the current status of ETs closer towards the strategy outlined above.

The analysis provided in this paper has effectively demonstrated the integration of dynamic LCAs and corresponding carbon-neutral growth rates into energy policy. However, the 
Pre-print of article published as: R. Kenny, C. Law, J.M. Pearce, “Towards Real Energy Economics: Energy Policy Driven by Life-Cycle Carbon Emission", Energy Policy 38, pp. 1969-1978, 2010. Available: http://dx.doi.org/10.1016/j.enpol.2009.11.078

deployment scenario outlined by the model is not a comprehensive analysis and does not attempt to accurately predict future renewable energy market share. The simulation exemplifies the need for a policy shift towards analyses with a focus on emitted and mitigated carbon rather than a foundation solely on the current economic system, which does not take climate-change related externalities into account. In addition, the model provides a tool that can be added to sophisticated modeling software in order to accurately advise policy.

The carbon neutral growth rate was particularly sensitive to the life cycle analyses used, which underscores the importance of systematic, third party dynamic LCAs for all energy technologies and their use to scientifically guide policy. Fthenakis (2007) attributes the lack of comparable LCAs to the absence of a consensus on the boundaries of the analysis. The development of a global consensus on boundaries surrounding LCAs will provide researchers with an established methodology that will help standardize the results of life cycle assessments. With this methodology in practice, questions regarding comparability between analysis results will be eliminated. The dependence of both the cannibalistic and carbon neutral growth rates on LCAs eliminates the possibility of incorporating future technologies in the simulation, as it would be impossible to determine the energy and carbon requirements of these hypothetical technologies. However both rates can be increased by reducing the carbon-intensive resources used in the manufacturing, construction and operation of ETs. Increased research into these technologies and other technologies at the development stage could provide the advancements required for more favorable growth rates.

In this example, small hydro, biomass, and geothermal are constrained by previous historic growth rates which is not an accurate restraint. As a comparison, the solar photovoltaic industry is currently growing at $110 \%$ annually (Solarbuzz, 2009) yet in decades past such growth rates would have been unfathomable. Therefore, the potential for rapid expansion of AETs exists given the proper policy incentives and technological advancements. These expansions could alter the constraints initially imposed on these technologies and increase their share in global electricity production.

\section{Conclusions}

The challenges involved in meeting increasing electricity demand while simultaneously reducing carbon dioxide emissions can be met by the large scale deployment of alternative energy technologies. However, deployment must be dependent on the life cycle carbon emissions of each viable technology. Currently employed static life cycle assessments incorrectly trivialize subtleties associated with rapid growth; this disparity enables the development of a global carbon Ponzi scheme wherein the carbon mitigation potential of technologies is hindered by large scale deployment. Dynamic life-cycle analyses offer a superior tool to evaluate deployment strategies for energy technologies. While there remains a need for rigorous simulation of carbon neutral growth rates on both global and local scales, carbon neutral growth rates paired with dynamic life-cycle assessments arm policy makers with standardized information needed to optimize electricity generation technology deployment for effective climate change mitigation. 
Pre-print of article published as: R. Kenny, C. Law, J.M. Pearce, “Towards Real Energy Economics: Energy Policy Driven by Life-Cycle Carbon Emission”, Energy Policy 38, pp. 1969-1978, 2010. Available: http://dx.doi.org/10.1016/j.enpol.2009.11.078

\section{Acknowledgments}

The authors would like to acknowledge helpful discussions with A. Buitenhaus, S. Keating, H. Nguyen, A. Nosrat, E. Shackles, and M. Urquhart. This work was supported by the National Science and Engineering Research Council.

\section{References}

Celik, A., Muneer, T., \& Clarke, P. (2007). An investigation into micro wind energy systems for their utilization in urban areas and their life cycle assessment. Proceedings of the Institution of Mechanical Engineers, Part A: Journal of Power and Energy, 221, 1107-1117. Demirbas, A. 2006. Global Renewable Energy Resources. Energy Sources, Part A: Recovery, Utilization, and Environmental Effects, 28, 779.

de Vries, B. J., van Vuuren, D. P., \& Hoogwijk, M. M., 2007. Renewable energy sources: Their global potential for the first-half of the 21 st century at a global level: An integrated approach. Energy Policy, 35, 2590-2610.

Fargione, J., Hill, J., Tilman, D., Polasky, S., Hawthorne, P., 2008. Land Clearing and the Biofuel Carbon Debt. Science, 319, 1235-1238.

Fridleifsson, et al., The possible role and contribution of geothermal energy to the mitigation of climate change. Paper presented at the IPCC Scoping Meeting on Renewable Energy Sources, Luebeck, Germany, 20-25 January 2008.

Fthenakis, V., Alsema, E., 2006. Photovoltaics energy payback times, greenhouse gas emissions and external costs: 2004-early 2005 status. Progress in Photovoltaics: Research and Applications, 14, 275-280.

Fthenakis, V. M.,, Kim, H. C., 2007. Greenhouse-gas emissions from solar electric- and nuclear power: A life-cycle study. Energy Policy, 35, 2549-2557.

Gagnon, L., Bélanger, C., \& Uchiyama, Y. 2002. Life-cycle assessment of electricity generation options: The status of research in year 2001. Energy Policy, 30, 1267-1278.

Gibson, T. A., 2005. NIMBY and the Civic Good. City and Community, 4, 381-401.

Goldemberg, J., Johansson, T. B., \& Anderson, D. (2004). World energy assessment: overview 2004 update. United Nations.

Hansen, J., Sato, M., 2004. Greenhouse gas growth rates. Proceedings of the National Academy of Sciences of the United States of America, 101, 16109-16114.

Hansen, J., Sato, M., Kharecha, P., Beerling, D., Berner, R., Masson-Delmotte, V., et al., 2008. Target Atmospheric CO2: Where Should Humanity Aim? The Open Atmospheric Science Journal, 2.

Hondo, H., 2005. Life cycle GHG emission analysis of power generation systems: Japanese case. Energy, 30, 2042-2056.

Intergovernmental Panel on Climate Change (IPCC), 2008a. Climate Change 2007: Synthesis Report. Intergovernmental Panel on Climate Change. Cambridge University Press, Cambridge, United Kingdom.

Intergovernmental Panel on Climate Change (IPCC), 2008b. Climate Change 2007: Mitigation of Climate Change. Intergovernmental Panel on Climate Change. Cambridge University Press, Cambridge, United Kingdom. 
Pre-print of article published as: R. Kenny, C. Law, J.M. Pearce, “Towards Real Energy Economics: Energy Policy Driven by Life-Cycle Carbon Emission", Energy Policy 38, pp. 1969-1978, 2010. Available: http://dx.doi.org/10.1016/j.enpol.2009.11.078

International Energy Agency (IEA), 2007. Renewables 2007: Global Status Report. International Energy Agency, IEA/OECD, Paris, France.

International Energy Agency (IEA), 2008a. Key Energy Statistics 2008. International Energy Agency, IEA/OECD, Paris, France.

International Energy Agency (IEA), 2008b. Energy Technology Perspectives 2008: Scenarios and Strategies to 2050. International Energy Agency, IEA/OECD, Paris, France

International Energy Agency (IEA), 2008c. World Energy Outlook 2008. International Energy Agency, IEA/OECD, Paris, France.

International Energy Agency (IEA), 2008d. Energy Statistics of OECD Countries: 2005/2006. International Energy Agency, IEA/OECD, Paris, France.

International Energy Agency (IEA), 2008e. Renewables Data for World. International Energy Agency, IEA/OECD, Paris, France.

International Energy Agency (IEA), 2009. Renewables Global Status Report Update 2009. International Energy Agency, IEA/OECD, Paris, France.

Jacobson, M. Z., 2009. Review of solutions to global warming, air pollution, and energy security. Energy \& Environmental Science, 2, 148-173.

Johansson, T. B., Kelly, H., Reddy, A. K., \& Williams, R. H., 1993. Renewable energy: Sources for fuels and electricity. Island Press, Washington, DC, United States.

Lechon, Y., de la Rua, C.,, Saez, R., 2008. Life Cycle Environmental Impacts of Electricity Production by Solar thermal Power Plants in Spain. Journal of Solar Energy Engineering, 130, 021012-7.

Martinez, E., Sanz, F., Pellegrini, S., Jimenez, E., \& Blanco, J. 2009. Life cycle assessment of a multi-megawatt wind turbine. Renewable Energy, 34, 667-673.

Mathur, J., Bansal, N. K.,, Wagner, H., 2004. Dynamic energy analysis to assess maximum growth rates in developing power generation capacity: case study of India. Energy Policy, 32, 281-287.

Mortimer, N. D. 1991. Energy analysis of renewable energy sources. Energy Policy, 19, 374385.

Mann, M.K., \& Spath, P.L. 1997. Life Cycle Assessment of a Biomass Gasification CombinedCycle Power System. National Renewable Energy Laboratory, Golden, CO, United States. Neuhoff, K., 2005. Large-Scale Deployment of Renewables for Electricity Generation. Oxf Rev Econ Policy, 21, 88-110.

Odeh, N. A., \& Cockerill, T. T. 2008. Life cycle analysis of UK coal fired power plants. Energy Conversion and Management, 49, 212-220.

Pacala, S., Socolow, R., 2004. Stabilization Wedges: Solving the Climate Problem for the Next 50 Years with Current Technologies. Science, 305, 968-972.

Pearce, J., 2002. Photovoltaics - A Path to Sustainable Futures. Futures, 34, 663-674.

Pearce, J. and Lau, A., 2002. Net Energy Analysis For Sustainable Energy Production From

Silicon Based Solar Cells, R. Cambell-Howe (Ed.), Proceedings of American Society of

Mechanical Engineers Solar 2002: Sunrise on the Reliable Energy Economy. 
Pre-print of article published as: R. Kenny, C. Law, J.M. Pearce, “Towards Real Energy Economics: Energy Policy Driven by Life-Cycle Carbon Emission", Energy Policy 38, pp. 1969-1978, 2010. Available: http://dx.doi.org/10.1016/j.enpol.2009.11.078

Pearce, J. M., 2008a. Thermodynamic limitations to nuclear energy deployment as a greenhouse gas mitigation technology. International Journal of Nuclear Governance, Economy and Ecology, 2, 113 - 130.

Pearce, J. M., 2008b. Limitations of Greenhouse Gas Mitigation Technologies Set by Rapid Growth and Energy Cannibalism. Proceedings of Klima 2008/Climate 2008.

Pearce, J.M. 2009. Optimizing Greenhouse Gas Mitigation Strategies to Suppress Energy

Cannibalism. $2^{\text {nd }}$ Climate Change Technology Conference Proceedings, paper 48.

Sims, R. E. H., Rogner, H.,, Gregory, K., 2003. Carbon emission and mitigation cost comparisons between fossil fuel, nuclear and renewable energy resources for electricity generation. Energy Policy, 31, 1315-1326.

Sims, R. E. H., 2004. Renewable energy: a response to climate change. Solar Energy, 76, 9-17. Solarbuzz, 2009. World PV Industry Report. Accessed 20 August, 2009. Available at http://www.solarbuzz.com/Marketbuzz2009-intro.htm SourceOECD database, 2009. Organization for Economic Co-operation and Development. IEA/OECD. Paris, France. Accessed 21 August 2009 Available at http://masetto.sourceoecd.org/vl=940203/cl=14/nw=1/rpsv/home.htm

Stern, N. H., \& Treasury, G. B., 2007. The economics of climate change. Cambridge University Press, Cambridge, UK.

Tahara, K., Kojima, T., Inaba, A., 1997. Evaluation of CO2 payback time of power plants by LCA. Energy Conversion and Management, 38, 615-620.

Tremeac, B., \& Meunier, F., 2009. Life cycle analysis of 4.5 MW and 250 W wind turbines. Renewable and Sustainable Energy Reviews, 13, 2104-2110.

Turner, J. A., 1999. A Realizable Renewable Energy Future. Science, 285, 687-689. Utility Wind Integration Group. 2006. Utility Wind Integration State of the Art. Accessed 21 August 2009. Available at http://www.uwig.org/UWIGWindIntegration052006.pdf.

World Energy Council, 2004. Comparison of Energy Systems using Life Cycle Assessment. World Wind Energy Association, 2008. World Wind Energy Report 2008. Bonn, Germany. Accessed 25 August, 2009. Available at http://www.wwindea.org/home/images/stories/worldwindenergyreport2008_s.pdf. 